\title{
Analisa Laju Sedimentasi Di Laguna Perairan Pamayangsari, Kabupaten Tasikmalaya
}

\author{
Jannisa Raska ${ }^{1^{*}}$, Petrus Subardjo ${ }^{1}$, Gentur Handoyo ${ }^{1}$ Dwi Haryo Ismunarti ${ }^{1}$ \\ dan Sugeng Widada ${ }^{1}$
}

\author{
${ }^{1}$ Program Studi Oseanografi, Jurusan Ilmu Kelautan, Fakultas Perikanan dan Ilmu Kelautan, \\ Universitas Diponegoro \\ *Email: raskajannisa@gmail.com
}

\begin{abstract}
Abstrak
Pantai Pamayangsari terletak di Kabupaten Tasikmalaya pada 108 $6^{\prime} 16,09^{\prime \prime}$ Bujur Timur - 108 $6^{\circ} 44,40^{\prime \prime}$ Bujur Timur dan 7046'23,47" Lintang Selatan - 7046'32,73" Lintang Selatan. Wilayah Pantai Pamayangsari di sebelah barat berbatasan dengan Kabupaten Garut, sebelah timur berbatasan dengan Kabupaten Ciamis, sebelah utara berbatasan dengan Kota Tasikmalaya dan Kabupaten Ciamis, serta di sebelah selatan berbatasan dengan Samudera Indonesia. Pantai Pamayangsari memiliki laguna yang airnya berasal dari air tawar Sungai Cilangla dan air asin dari laut. Air tersebut membawa material sedimen yang kemudian masuk ke daerah laguna. Kondisi di sekitar laguna dikelilingi oleh hutan rawa mangrove dan daerahnya bersubstrat pasir, sehingga di laguna tersebut mengalami sedimentasi yang cukup tinggi. Proses sedimentasi yang terjadi akan menimbulkan pendangkalan yang dapat menghambat aliran sungai ke laut dan menyebabkan banjir. Penelitian ini bertujuan untuk mengetahui nilai laju sedimentasi di laguna Pantai Pamayangsari, Kabupaten Tasikmalaya. Penetian ini dilakukan dalam dua tahap, yaitu penelitian lapangan pada tanggal 2 - 16 Juli 2019 dan analisa laboratorium pada tanggal 18 September hingga 3 Oktober 2019. Data utama pada penelitian ini adalah sampel sedimen di sediment trap. Data pendukung pada penelitian ini meliputi debit sungai dari Dinas Pekerjaan Umum Kabupaten Tasikmalaya tahun 2019, data angin dari European Centre for Medium-Range Weather Forecast bulan Januari 2014 - Juli 2019, dan Peta Database of Global Administrative Areas (GADM). Metode penelitian yang digunakan adalah metode kuantitatif. Hasil penelitian menunjukkan nilai rata - rata laju sedimentasi di setiap stasiun berkisar antara 10,494-12,496 gr/m $\mathrm{m}^{2}$ /hari. Total nilai laju sedimentasi dari setiap stasiun pada pengambilan pertama $7,237 \mathrm{gr} / \mathrm{m}^{2} / \mathrm{hari}$ dan pengambilan kedua $16,354 \mathrm{gr} / \mathrm{m}^{2}$ /hari. Jenis sedimen di laguna Perairan Pamayangsari yaitu pasir (sand), lanau (silt) dan lempung (clay).
\end{abstract}

Kata Kunci: Laju Sedimentasi, Jenis Sedimen, Laguna

\section{Abstract}

Coastal area of Pamayangsari islocated in Tasikmalaya, 108 ${ }^{\circ} 16,09^{\prime \prime}$ East Longitude - 108 $6^{\prime} 44,40^{\prime \prime}$ East Longitude and 7०46'23,47" South Latitude - 7० 46'32,73" South Latitude. The westest of coastal area of Pamayangsari is Garut Regency, the eastest is Ciamis Regency, the northest is Tasikmalaya City and Ciamis Regency, and the southtest is the Indian Ocean. Coastal area of Pamayangsari has an lagoon that contain water from the fresh water of the Cilangla River and salt water from the sea. The water carries sediment material which then enters the lagoon area. The conditions around the lagoon are surrounded by mangrove swamp forest and the area has sand substrate, so that the lagoon experiences high sedimentation. The sedimentation process that occurs will cause siltation which can hamper the flow of the river into the sea and cause flooding. This research aims to determine the value of sedimentation rates in lagoon of the Pamayangsari's coastal area. This research is conducted in two stages, which are fieldwork on July 2 nd - 16th 2019 and laboratory analysis on September 18th until October 3rd, 2019. The main data in this research is samples from sediment trap. Supporting data in this research include, river discharge from the Tasikmalaya District Public Works Office in 2019, wind data from the European Center for Medium-Range Weather Forecast in January 2014 - July 2019, and the Database of Global Administrative Areas (GADM) Map. The research method uses a quantitative method. The results show that the average value of sedimentation rate at each station ranged from $10.494-12.496 \mathrm{gr} / \mathrm{m}^{2} /$ day. The total value of sedimentation rate from each station on the first taking is $7,237 \mathrm{gr} / \mathrm{m}^{2} /$ day and the second taking is $16,354 \mathrm{gr} /$ $\mathrm{m}^{2} /$ day. Types of sediments in lagoon are sand, silt and clay

Keywords: Sedimentation Rate, Types of Sediments, Lagoon 


\section{PENDAHULUAN}

Pantai merupakan daerah yang sangat rentan mengalami perubahan. Perubahan tersebut dapat terjadi karena sebagian besar sedimen yang terbawa dari laut terbuka tidak semuanya terendapkan di laut yang lebih dalam tetapi hanyut oleh arus pasang surut yang masuk ke bayhead dan bayside. Kondisi tersebut menyebabkan adanya sandbar di daerah pantai dan juga membuat struktur sedimen menjadi tidak padat (Lobeck, 1939).

Pantai Pamayangsari merupakan daerah pesisir di Kabupaten Tasikmalaya, Provinsi Jawa Barat, yang memiliki peran sangat penting dalam kehidupan manusia, terutama di bidang sosial dan ekonomi. Pantai Pamayangsari terletak di tiga Kecamatan, yaitu Kecamatan Cipatujah, Karangnunggal, dan Cikalong. Pantai Pamayangsari merupakan wilayah laut terbuka karena berbatasan langsung dengan Samudera Hindia di bagian Selatan.

Menurut petugas Kecamatan Cipatujah, di Pantai Pamayangsari terdapat laguna yang berasal dari air tawar Sungai Cilangla dan air asin dari laut, yang dipisahkan oleh sand bar, sehingga di laguna tersebut mengalami sedimentasi yang cukup tinggi. Proses sedimentasi yang terjadi akan menimbulkan pendangkalan yang dapat menghambat aliran sungai ke laut dan menyebabkan banjir. Kondisi di sekitar laguna Sungai Cilangla dikelilingi oleh hutan rawa mangrove dan daerahnya bersubstrat pasir. Penelitian terkait laju sedimentasi terdahulu oleh Saputra et al. (2017) di laguna Segara Anakan, Cilacap, menjelaskan bahwa kondisi substrat dipengaruhioleh aktivitas manusia yang berasal dari daratan dan juga oleh faktor 2 hidro- oseanografi, seperti arus, pasang surut, dan gelombang.

Aktivitas alam dan manusia tersebut membuat adanya perubahan pada kondisi di laguna Pantai Pamayangsari. Kondisi yang rentan mengalami perubahan tersebut, terjadi akibat dari adanya sedimentasi. Oleh karena itu, diperlukan kajian untuk mengetahui kecepatan sedimentasi di laguna Perairan Pamayangsari, Kabupaten Tasikmalaya.

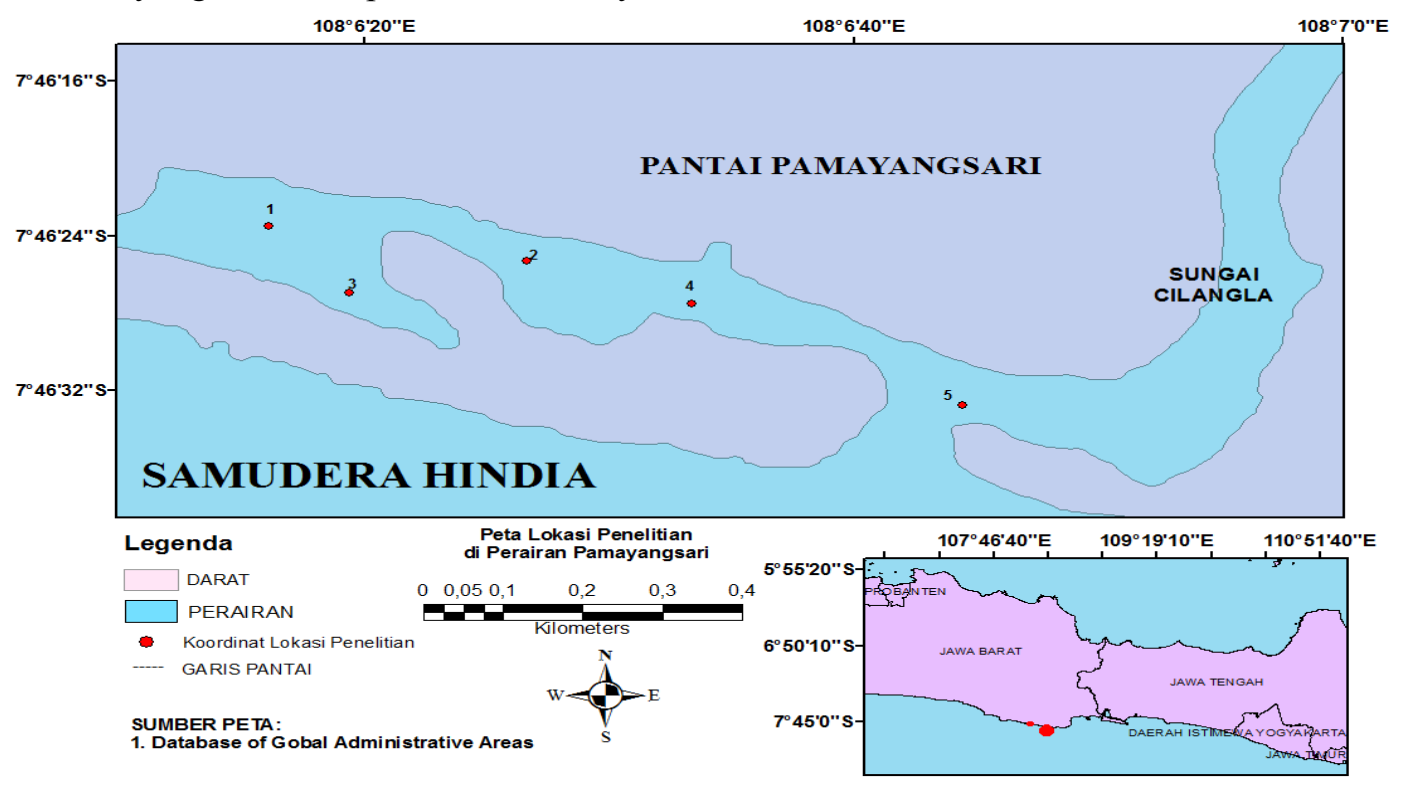

Gambar 1. Peta Lokasi Penelitian (Penelitian, 2019)

\section{MATERI DAN METODE PENELITIAN \\ MATERI}

Materi yang digunakan dalam penelitian ini dibagi menjadi dua data, yaitu data utama dan data pendukung. Data utama yang digunakan dalam penelitian ini adalah sampel sedimen. Data pendukung merupakan data pelengkap untuk mendukung data utama pada penelitian. Data pendukung yang digunakan dalam penelitian ini antara lain debit sungai Cilangla tahun 2019 dari Dinas Pekerjaan Umum Kabupaten Tasikmalaya, data angin dari European Center for Medium-Range Weather Forecast bulan 
Januari 2014 hingga Juli 2019, dan Peta Database of Global Administrative Areas skala $1: 10.000$ tahun 2018.

\section{METODE}

Metode yang digunakan dalam penelitian ini merupakan metode kuantitatif. Metode kuantitatif adalah metode penelitian yang memenuhi kaidah ilmiah yang konkret, objektif, dan terukur. Metode kuantitatif digunakan untuk meneliti kondisi alam dengan akurat dan tepat agar dapat memperoleh gambaran pada daerah penelitian. Analisis metode kuantitatif pada dasarnya menggunakan statistik dan model, sedangkan penelitiannya berupa angka - angka (Sugiyono, 2008).

Penelitian ini menggunakan lokasi pengambilan sampel yang berdasarkan metode purposive sampling, yaitu metode pengambilan sampel yang dipilih untuk menentukan sampel penelitian, yang bertujuan agar data yang diperoleh bisa representative, karena berdasarkan pada titik stasiun yang dapat mewakili keadaan di lokasi penelitian. Data yang diambil di lapangan berupa koordinat daerah penelitian menggunakan GPS dan sampel sedimen menggunakan sediment trap selama 14 hari.

Pengambilan sampel sedimen pada lokasi penelitian menggunakan sediment trap. Sediment trap berbentuk silinder yang terbuat dari pipa berdiameter $10 \mathrm{~cm}$ dan tinggi $50 \mathrm{~cm}$. Bagian bawah pipa ditutup menggunakan semen, yang berfungsi sebagai pemberat agar alat tidak hanyut. Pada penelitian ini, sediment trap digunakan untuk mengetahui kecepatan sedimentasi yang terjadi akibat faktor oseanografi. Lokasi penempatan sediment trap sebanyak 5 stasiun yang tersebar di daerah laguna. Sampel sedimen disimpan di dasar perairan laguna selama 14 hari. Tiap stasiun mempunyai dua sediment trap dengan pengambilan sampel sedimen sebanyak dua kali pada hari ke-7 dan ke-14.

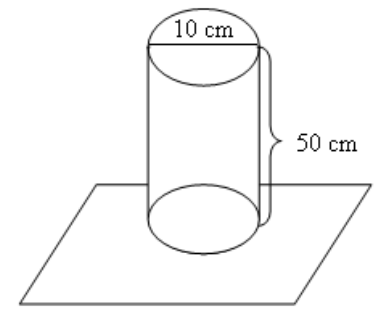

Gambar 2. Sediment trap

(Buchanan, 1984 dalam Holme dan Intyre, 1984)

Lokasi pengukuran laju sedimentasi terbagi menjadi lima stasiun. Titik - titik stasiun dipilih berdasarkan adanya penambahan daratan yang terjadi di lokasi tersebut, dengan asumsi bahwa di posisi tersebut terjadi proses pengendapan dan di setiap titik di lokasi dianggap mewakili nilai laju sedimentasi dari keadaan sebenarnya (Aritonang et al., 2016). Sampel sedimen diambil menggunakan sedimentrap untuk mengetahui nilai laju sedimentasi dan ukuran butir sedimen di lokasi penelitian. Lokasi pertama berada di sebelah Barat Laut sandbar. Lokasi pertama ini merupakan lokasi untuk mewakili daerah yang membelok dan dilalui oleh arus yang membawa material dari titik lima, empat, dan dua. Lokasi kedua berada di sebelah Utara sandbar. Lokasi kedua untuk mewakili daerah yang hanya dilalui oleh arus yang membawa material dari titik lima dan empat. Lokasi ketiga berada di sebelah Barat sandbar. Lokasi ketiga untuk mewakili daerah yang memiliki nilai laju sedimentasi terbesar, karena memiliki kecepatan arus yang rendah. Lokasi keempat berada di sebelah Utara sandbar, untuk mewakili daerah pembuangan tambak udang, dan lokasi kelima berada di sebelah Timur Laut, untuk mewakili lokasi tempat masuknya arus dari sungai dan laut.

Data debit sungai didapatkan dari Dinas Pekerjaan Umum Kabupaten Tasikmalaya. Data angin tahunan yang diperolah dari European Centre for Medium-Range Weather Forecasts (ECMWF), kemudian disajikan dalam Microsoft Excel dan diklasifikasikan berdasarkan empat musim, yaitu Musim Barat, Musim Timur, Musim Peralihan I, dan Musim Peralihan II. Data angin dari ECMWF yang digunakan yaitu dari bulan Januari 2014 hingga bulan Juli 2019, dan selanjutnya diolah dengan 
menggunakan Wrplot view untuk memperoleh kondisi dominan angin yang disajikan dalam mawar angin (windrose). Berikut adalah langkah yang dilakukan dalam peramalan gelombang menggunakan metode Svrdrup, Munk, dan Bretschneider (SMB):

1. Menghitung panjang fetch pada peta dengan memperhatikan skala. Fetch rerata efektif dihitung menggunakan persamaan berikut:

$\mathrm{FE}=\frac{\sum x i \operatorname{Cos} \alpha}{\sum \operatorname{Cos} \alpha}$

Keterangan:

FE: fetch rerata efektif

Xi: panjang fetch

2. Mengitung nilai kecepatan angin pada ketinggian $10 \mathrm{~m}$ (U10), menghitung koreksi stabilitas (Ut), serta menghitung koefisien gesek (UA). Sedangkan untuk koreksi efek lokasi tidak diperhitungkan dikarenakan data angin ECMWF yang diperoleh merupakan data angin hasil pengukuran di laut.

3. Menghitung durasi kecepatan angin ( $\mathrm{t}$ ) dan koreksi durasi angin. Koreksi durasi angin menjadi penting dikarenakan angin hasil pengukuran hanya merupakan angin pengukuran sesaat sehingga diperlukan mencari rata-rata dari durasi angin

4. Menghitung nilai durasi kritis atau durasi minimum sebagai landasan mengetahui bahwa pembangkitan dibatasi oleh durasi atau oleh fetch

5. Mengitung Hs dan Ts.

Metode analisa laju sedimentasi dilakukan dengan tahapan sebagai berikut:

1. Shieving, fungsi shieving untuk mengetahui ukuran butir berdasarkan skala wentworth menggunakan alat shieve shaker.

2. Pippeting, fungsi pippeting (pemipetan) untuk melihat distribusi ukuran butir sampel sedimen yang dianalisa. Pemipetan ini dilakukan pada tabung ukur 1000 mililiter yang didalamnya berisi air aquades dan sampel sedimen. Sampel di dalam tabung ukur selanjutnya diaduk menggunakan alat pengaduk. Selanjutnya sampel diambil dengan waktu jarak pemipetan (tabel 1). Hasil dari pemipetan diletakkan pada botol sampel kecil.

Tabel 1. Jarak Tenggelam dan Waktu Pemipetan

\begin{tabular}{cccc}
\hline No & $\begin{array}{c}\text { Waktu (Jam, Menit, } \\
\text { Detik) }\end{array}$ & $\begin{array}{c}\text { Jarak Tenggelam } \\
(\mathbf{c m})\end{array}$ & $\begin{array}{c}\text { Diameter } \\
\text { (cm) }\end{array}$ \\
\hline 1 & 000058 & 20 & 0,0625 \\
2 & 000156 & 10 & 0,0312 \\
3 & 000744 & 10 & 0,0156 \\
4 & 003100 & 10 & 0,0078 \\
5 & 023000 & 10 & 0,0039 \\
\hline
\end{tabular}

Buchanan, 1984 dalam Holme dan Intrye, 1984

3. Vacuum pumping, fungsi pumping untuk memisahkan air dan sedimen yang disaring pada kertas saring.

4. Sampel pada kertas saring selanjutnya dikeringkan di oven pada suhu $105^{\circ} \mathrm{C}$ selama 10 menit. Sampel yang sudah di oven lalu ditimbang dan dilakukan perhitungan nilai laju sedimentasi. Rumus analisis laju sedimentasi ini menggunakan metode menurut Buchanan (1984) dalam Holme dan Intyre (1984), yaitu:

$$
\begin{aligned}
\text { Laju sedimentasi } & =\frac{10000}{\pi r^{2}}(A-B) \frac{\frac{g r}{\mathrm{~m}^{2}}}{\mathrm{hari}} \\
& =\frac{10}{\pi r^{2}}(A-B) \frac{\frac{\mathrm{kg}}{\mathrm{m}^{2}}}{\text { hari }}
\end{aligned}
$$




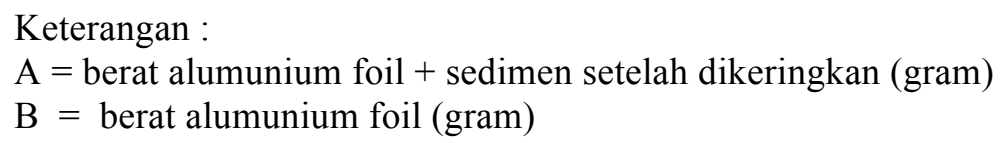

Menurut Triatmodjo (1999), arus sejajar pantai dapat ditimbulkan oleh gelombang yang pecah membentuk sudut terhadap garis pantai. Parameter terpenting dalam menentukan arus ini adalah gelombang pecah. Perhitungan arus sejajar pantai dari sudut datang gelombang pecah diberikan oleh persamaan Longuct - Higgins sebagai berikut:

$$
\mathrm{V}=1.17\left(\mathrm{~g} \mathrm{H}_{\mathrm{b}}\right)^{1 / 2} \sin \alpha_{\mathrm{b}} \cos \alpha_{\mathrm{b}}
$$

\section{HASIL DAN PEMBAHASAN}

\section{LAJU SEDIMENTASI}

Berdasarkan perhitungan laju sedimentasi pada sampel sedimen yang telah dilakukan, maka diperoleh hasil laju sedimentasi yang berbeda di setiap lokasi pengamatan. Pada pengambilan ke-1, nilai laju sedimentasi tertinggi yaitu pada lokasi pengamatan ke 2, sedangkan nilai laju sedimentasi terendah yaitu pada lokasi pengamatan ke-4. Pada pengambilan ke-2, nilai laju sedimentasi tertinggi yaitu pada lokasi pengamatan ke-3, sedangkan nilai laju sedimentasi terendah yaitu pada lokasi pengamatan ke-4. Rata - rata nilai laju sedimentasi pada saat pengambilan pertama yaitu sebesar $7,237 \mathrm{gr} / \mathrm{m}^{2} / \mathrm{hari}$. Rata rata nilai laju sedimentasi pada saat pengambilan ke dua yaitu sebesar $16,354 \mathrm{gr} / \mathrm{m}^{2} / \mathrm{hari}$. Hasil perhitungan nilai laju sedimentasi di setiap lokasi pengamatan dapat dilihat pada tabel 2 .

Tabel 2. Hasil Rata - Rata Laju Sedimentasi di Lokasi Pengamatan

\begin{tabular}{|c|c|c|c|}
\hline \multirow{2}{*}{$\begin{array}{c}\text { Lokasi } \\
\text { Pengamatan }\end{array}$} & \multicolumn{2}{|c|}{ Nilai Laju Sedimentasi (gr/m2/hari) } & \multirow[t]{2}{*}{ Rata - rata (gr/m2/hari) } \\
\hline & 09-Jul-19 & 16-Jul-19 & \\
\hline 1 & 8.311 & 16.621 & 12.466 \\
\hline 2 & 8.614 & 15.226 & 11.920 \\
\hline 3 & 7.522 & 17.470 & 12.496 \\
\hline 4 & 4.853 & 16.136 & 10.494 \\
\hline 5 & 6.885 & 16.318 & 11.601 \\
\hline $\begin{array}{l}\text { Rata - Rata } \\
\left(\mathrm{gr} / \mathrm{m}^{2} / \mathrm{hari}\right)\end{array}$ & 7.237 & 16.354 & \\
\hline
\end{tabular}

\section{Ukuran Butir Sedimen}

Data ukuran butir sedimen digunakan untuk mengetahui jenis sedimen yang berada di laguna perairan Pamayangsari, Kabupaten Tasikmalaya pada setiap lokasi pengamatan. Pengolahan ukuran butir menggunakan persen kumulatif dan segitiga Shepard untuk menentukan jenis sedimen pada setiap lokasi. Hasil dari pengolahan sedimen dapat dilihat pada Tabel 3. 
Tabel 3. Jenis - Jenis Sedimen Pada Lokasi Pengamatan

\begin{tabular}{ccccccc}
\hline \multirow{2}{*}{ Tanggal } & \multirow{2}{*}{$\begin{array}{c}\text { Lokasi } \\
\text { Pengamatan }\end{array}$} & $\begin{array}{c}\text { Gravel } \\
(\%)\end{array}$ & $\begin{array}{c}\text { Sand } \\
(\%)\end{array}$ & $\begin{array}{c}\text { Silt } \\
(\%)\end{array}$ & $\begin{array}{c}\text { Clay } \\
(\%)\end{array}$ & $\begin{array}{c}\text { Jenis } \\
\text { Sedimen }\end{array}$ \\
\cline { 3 - 6 } & 1 & 0 & 99.375 & 0.495 & 0.130 & Sand \\
\multirow{2}{*}{ 09-Jul-19 } & 2 & 0 & 99.409 & 0.471 & 0.121 & Sand \\
& 3 & 0 & 99.385 & 0.481 & 0.134 & Sand \\
& 4 & 0 & 99.581 & 0.312 & 0.107 & Sand \\
& 5 & 0 & 99.119 & 0.753 & 0.128 & Sand \\
\hline \multirow{3}{*}{ 16-Jul-19 } & 1 & 0 & 99.353 & 0.510 & 0.137 & Sand \\
& 2 & 0 & 99.406 & 0.481 & 0.114 & Sand \\
& 3 & 0 & 98.396 & 1.420 & 0.184 & Sand \\
& 4 & 0 & 99.468 & 0.433 & 0.099 & Sand \\
& 5 & 0 & 99.135 & 0.683 & 0.182 & Sand \\
\hline
\end{tabular}

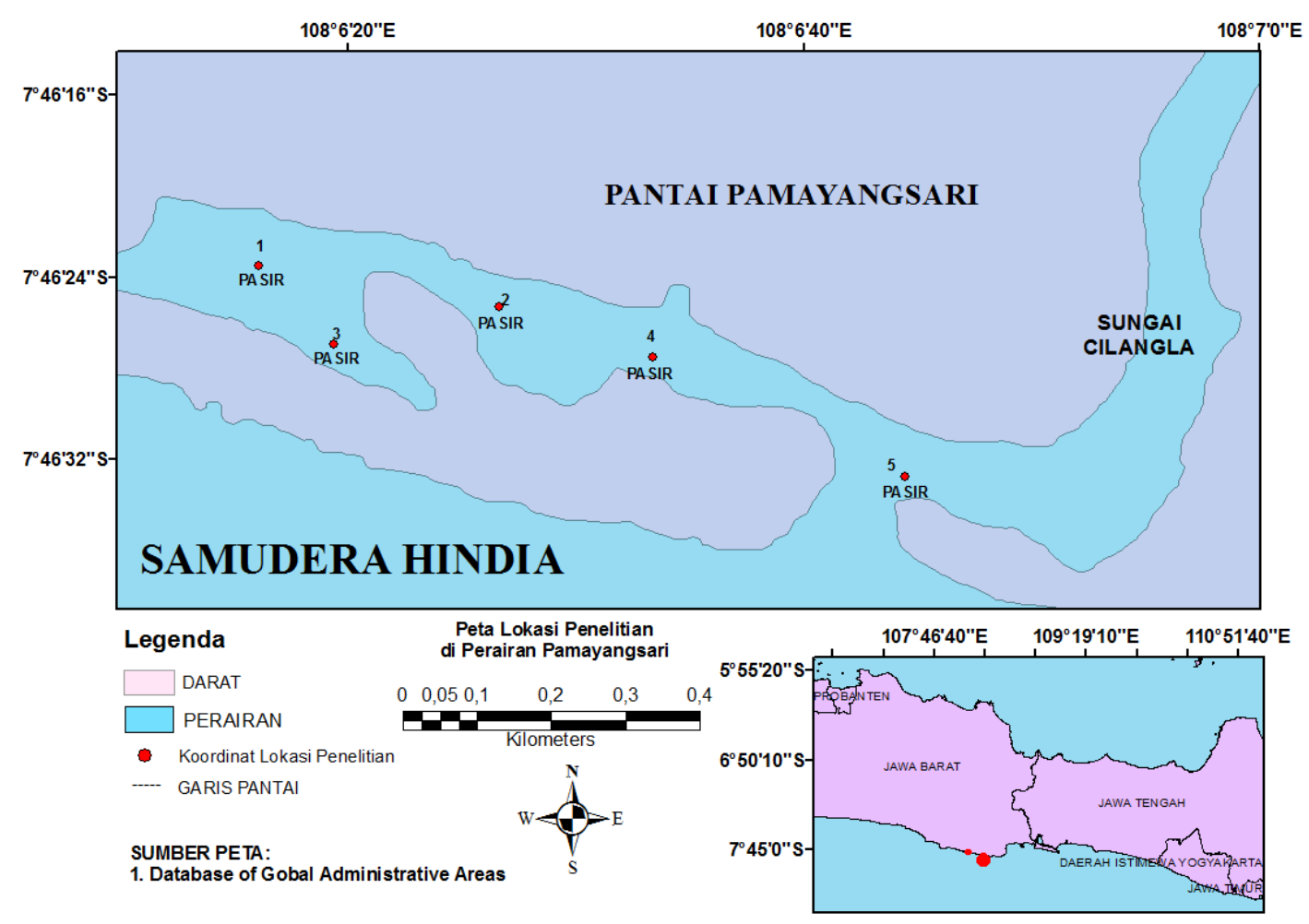

Gambar 3. Peta Sebaran Jenis Sedimen di Lokasi Pengamatan

\section{Debit Sungai}

Pengukuran debit sungai ini telah dilakukan oleh Dinas Pekerjaan Umum Tata Ruang Perumahan dan Permukiman (DPUPR) setiap bulan pada tahun 2019 di sungai Cilangla. Hasil perhitungan data debit sungai dapat dilihat pada Tabel 4. Berdasarkan tabel 4, diketahui bahwa debit air Sungai Cilangla setiap bulan pada tahun 2019 memiliki debit yang berbeda - beda. Debit air Sungai Cilangla terendah sebesar 2,72 $\mathrm{m}^{3} /$ detik terjadi pada bulan Agustus 2019 dan debit air Sungai Cilangla terbesar sebesar $32,31 \mathrm{~m}^{3} /$ detik terjadi pada bulan Februari 2019. 
Tabel 4. Debit Sungai Cilangla (Dinas Pekerjaan Umum Tata Ruang Perumahan dan Permukiman (DPUPR), 2019)

\begin{tabular}{cc}
\hline Bulan & Debit Sungai \\
\hline Januari & 23,04 \\
Februari & 32,31 \\
Maret & 20,38 \\
April & 21,51 \\
Mei & 16,41 \\
Juni & 10,86 \\
Juli & 7,00 \\
Agustus & 2,72 \\
September & 4,15 \\
Oktober & 9,71 \\
November & 18,97 \\
Desember & 20,05 \\
Total & 178,11 \\
\hline
\end{tabular}

\section{Peramalan Gelombang}

Nilai tinggi gelombang signifikan dan periode gelombang signifikan setiap musim selama lima tahun dapat dilihat pada Tabel 5.

Tabel 5. Tinggi dan Periode Signifikan setiap musim (Januari 2014 - Juli 2019)

\begin{tabular}{lcccccc}
\hline \multirow{2}{*}{ Musim } & \multicolumn{3}{c}{ Tinggi Gelombang } & \multicolumn{3}{c}{ Periode Gelombang } \\
\cline { 2 - 7 } & Hmax (m) & Hs (m) & Hmin (m) & Tmax (s) & Ts (s) & Tmin (s) \\
\hline Barat & 1.867 & 1.605 & 0.237 & 14.236 & 10.819 & 0.330 \\
Peralihan I & 1.076 & 1.069 & 0.050 & 12.819 & 9.175 & 0.168 \\
Timur & 1.240 & 1.166 & 0.416 & 13.439 & 9.893 & 0.269 \\
Peralihan II & 1.838 & 1.645 & 0.420 & 15.323 & 9.026 & 0.165 \\
\hline
\end{tabular}

Hasil peramalan gelombang yang dilakukan selama lima tahun, Januari 2014 - Juli 2019, didapatkan nilai tinggi gelombang signifikan (Hs) dan periode gelombang signifikan (Ts) dari setiap musim, yaitu musim Barat, musim Peralihan I, musim Timur, dan juga musim Peralihan II. Nilai dari Hs dan Ts tersebut digunakan untuk menghitung nilai kecepatan arus sejajar pantai (longshore current). Nilai kecepatan arus sejajar pantai dikelompokkan menjadi empat musim sesuai dengan peramalan gelombang yang dilakukan. Nilai kecepatan arus sejajar pantai tersebut dapat dilihat pada Tabel 6 .

Berdasarkan nilai hasil pada Tabel 6 menunjukkan bahwa kecepatan longshore current terbesar pada musim peralihan II, yaitu sebesar 3,097 m/s dan gelombang pecah membentuk sudut terhadap garis pantai sebesar $49,113^{\circ}$. Pada musim Peralihan I memiliki kecepatan longshore current terendah, yaitu sebesar $2,483 \mathrm{~m} / \mathrm{s}$ dengan sudut yang dibentuk oleh gelombang pecah terhadap garis pantai sebesar $35,732^{\circ}$. Pada musim Timur, kecepatan longshore current sebesar $2,565 \mathrm{~m} / \mathrm{s}$ dengan sudut yang dibentuk gelombang pecah dengan angin dari arah Barat Daya, yaitu sebesar $38,829^{\circ}$. Pada musim Barat, kecepatan longshore current sebesar $2,870 \mathrm{~m} / \mathrm{s}$ dan gelombang pecah membentuk sudut sebesar $50,714^{\circ}$ terhadap garis pantai. 
Tabel 6. Nilai Kecepatan Arus Sejajar Pantai di Perairan Pamayangsari

\begin{tabular}{|c|c|c|c|c|}
\hline \multirow[b]{2}{*}{ Parameter } & \multicolumn{4}{|c|}{ Data Peramalan } \\
\hline & Musim Barat & $\begin{array}{c}\text { Musim } \\
\text { Peralihan I }\end{array}$ & Musim Timur & $\begin{array}{c}\text { Musim } \\
\text { Peralihan II }\end{array}$ \\
\hline $\operatorname{Lo}(\mathbf{m} / \mathbf{s})$ & 182.599 & 131,321 & 152,679 & 127,091 \\
\hline $\operatorname{Co}(\mathbf{m} / \mathbf{s})$ & 16,878 & 14,312 & 15,433 & 14,081 \\
\hline $\mathbf{d} / \mathbf{L}$ & 0,05132 & 0,05 & 0,051 & 0,05082 \\
\hline $\begin{array}{l}\text { Klasifikasi } \\
\text { Perairan }\end{array}$ & Transisi & Transisi & Transisi & Transisi \\
\hline $\mathbf{L}(\mathbf{m})$ & 38,971 & 40 & 39,216 & 39,355 \\
\hline $\mathrm{C}(\mathrm{m} / \mathrm{s})$ & 5,266 & 4.351 & 4,769 & 4,351 \\
\hline Hb (m) & 2,554 & 2,043 & 2,054 & 2,917 \\
\hline db (m) & 1,583 & 1,322 & 1,261 & 2,217 \\
\hline$\alpha_{b}\left({ }^{\circ}\right)$ & 50,714 & 35,732 & 38,829 & 49,113 \\
\hline $\mathbf{V}(\mathbf{m} / \mathbf{s})$ & 2,870 & 2,483 & 2,565 & 3,097 \\
\hline $\mathrm{Cb}(\mathrm{m} / \mathrm{s})$ & 3,941 & 3,601 & 3,517 & 4,664 \\
\hline P1 kg m/det & $15.835,234$ & $8.955,667$ & $9.109,434$ & $24.683,848$ \\
\hline Qs $\left(\mathrm{m}^{3} / \mathrm{hari}\right)$ & $55.961,717$ & $31.649,327$ & $32.192,739$ & $87.232,719$ \\
\hline $\begin{array}{c}\text { Qs } \\
\left(\mathbf{m}^{3} / \text { tahun) }\right.\end{array}$ & $20.427 .451,86$ & $11.552 .810,43$ & $11.751 .169,86$ & $31.842 .163,92$ \\
\hline
\end{tabular}

\section{PEMBAHASAN}

Berdasarkan hasil yang diperoleh, nilai laju sedimentasi di setiap lokasi berbeda. Nilai laju sedimentasi terkecil diketahui terdapat pada lokasi keempat, yaitu sebesar $10.494 \mathrm{gr} / \mathrm{m}^{2} / \mathrm{hari}$. Hal tersebut terjadi karena lokasi keempat adalah tempat mengalirnya arus dari hulu sungai, walaupun di lokasi ke empat merupakan tempat pembuangan dari tambak udang. Menurut Salahuddin et al. (2012), limbah udang yang dibuang langsung ke muara berupa unsur organik, biasanya sisa pakan, dan kegiatan tersebut dapat mengganggu keseimbangan ekosistem pantai. Akumulasi unsur organik bisa meningkatkan populasi alga yang mengganggu komunitas ikan. Akumulasi dari limbah tambak udang tersebut terbawa oleh arus dari laut dan sungai menuju lokasi yang menjauhi masuknya air sungai dan laut, ke arah Barat sesuai dengan Aritonang et al. (2016) bahwa kecepatan arus yang rendah akan meningkatkan pengendapan yang tinggi.

Nilai laju sedimentasi pada lokasi ketiga adalah lokasi yang memiliki nilai laju sedimentasi terbesar, yaitu sebesar $12.496 \mathrm{gr} / \mathrm{m}^{2} /$ hari. Keadaan di lokasi ketiga ini jauh dari inlet air sungai dan laut, sehingga arus yang berada di sekitar lokasi ketiga pun tidak sebesar pada lokasi lainnya. Menurut pendapat Kepala Bidang Sumber Daya Air Dinas Pekerjaan Umum dan Permukiman Rumah Tangga, bahwa semakin jauh lokasi dari sungai, maka ukuran sedimen yang ada akan semakin kecil, karena arus yang memengaruhi ukuran butir sedimen akan semakin kecil. Hal ini sesuai dengan pernyataan Aritonang et al. (2016) bahwa ukuran partikel sedimen yang lebih kecil atau halus akan semakin mudah terendapkan.

Berdasarkan data debit sungai yang dapat dilihat pada Tabel 4. Debit Sungai Cilangla, diketahui debit sungai tertinggi pada bulan Februari 2019 yaitu sebesar $32.31 \mathrm{~m}^{3} /$ det dan debit sungai terkecil pada bulan Agustus 2019 yaitu sebesar $2.72 \mathrm{~m}^{3} /$ det. Nilai rata - rata debit Sungai Cilangla selama tahun 2019 sebesar $14.843 \mathrm{~m}^{3} /$ det. Menurut Triatmodjo (1999) dalam Srijati et al. (2017), salah satu faktor yang mempengaruhi sedimentasi adalah debit sungai. Debit sungai akan mengerosi sedimen dan membawa sedimen ke arah hilir, kemudian diendapkan ketika kecepatan aliran melambat. Ketika debit aliran besar maka sedimen yang tererosi juga semakin bertambah banyak, sehingga semakin banyak material sedimen yang mengalami pengendapan atau sedimentasi.

Menurut Elliott dan Whitfield (2011), laguna adalah ekosistem yang memiliki wilayahnya sendiri tetapi tidak dapat berfungsi jika tidak mendapatkan pengaruh dari lingkungan sekitarnya. Oleh karena itu, pada penelitian ini, debit sungai dan arus sejajar pantai menjadi faktor dari oseanografi yang 
memengaruhi proses sedimentasi di laguna, sesuai dengan pendapat Triatmodjo (1999) bahwa debit sungai dan arus sejajar pantai menjadi faktor yang memengaruhi proses sedimentasi di laguna. Angkutan sedimen yang berasal dari laut terbawa menuju laguna oleh arus, dan angkutan sedimen dari laut dan hulu sungai akan bertemu di muara sungai yang kemudian akan terendapkan di laguna.

Selain dari debit sungai, arus sejajar pantai juga memengaruhi sedimentasi yang terjadi di laguna. Arah dominan dari longshore current pada musim Peralihan I, Musim Timur, dan Peralihan II memiliki arah yang sama, yaitu berasal dari arah Barat Daya. Arah angin dominan pada musim Barat memiliki arah angin dari Utara. Kecepatan longshore current terbesar selama lima tahun, yaitu pada saat Musim Peralihan II sebesar $3.097 \mathrm{~m} /$ det dan kecepatan arus terendah yaitu pada Musim Peralihan I sebesar $2.483 \mathrm{~m} /$ det. Menurut Ayunarita et al. (2017), arus sejajar pantai umumnya mempunyai kecepatan rendah, tetapi sangat memengaruhi proses littoral transport, karena bergerak sepanjang pantai dalam waktu yang lama dan terus menerus selama ada gelombang. Longshore current yang membawa angkutan sedimen sepanjang pantai akan masuk ke muara sungai, yang kemudian akan terakumulasi di laguna Perairan Pamayangsari, hal ini yang menyebabkan terjadinya sedimentasi. Kecepatan arus sepanjang pantai yang terjadi di setiap musim dipengaruhi oleh sudut gelombang pecah, yang kemudian memengaruhi angkutan sedimen sepanjang pantai (Triatmodjo, 1999). Angkutan sedimen yang berasal dari sungai dan laut setiap musimnya akan mengakibatkan pendangkalan di daerah laguna. Sedimentasi yang terjadi di Perairan Pamayangsari ini membuat banyak kerugian bagi masyarakat sekitar. Salah satunya, yaitu terjadi banjir di daerah sekitar laguna, karena laguna tersebut tidak dapat menampung air yang datang dari hulu sungai dan juga air yang masuk dari laut terbuka karena adanya pendangkalan. Perairan Pamayangsari merupakan tipe perairan berpasir, dan memiliki kondisi substrat yang kurang stabil karena sangat dipengaruhi oleh gelombang pecah yang besar di sepanjang pantai (Suryani et al., 2013).

Hasil analisis ukuran butir di Perairan Pamayangsari diketahui jenis sedimennya adalah pasir (sand), lanau (silt), dan lempung (clay) yang dapat dilihat pada lampiran 2. Laguna merupakan tempat bertemunya arus air sungai yang mengalir ke laut dengan arus yang keluar masuk ke sungai. Aktivitas ini yang dapat menyebabkan terjadinya sedimentasi, baik yang berasal dari sungai maupun dari laut. Menurut Elliott dan Whitfield (2011) arus menjadi salah satu faktor yang memengaruhi sedimentasi, dimana sedimen dengan diameter kecil akan tererosi oleh arus. Akibat dari hal tersebut adalah seluruh material sedimen dengan segala ukuran kemungkinan akan tererosi dan terbawa oleh arus sungai dan arus dari laut ke daerah laguna.

\section{KESIMPULAN}

Berdasarkan hasil penelitian yang didapatkan, diperoleh kesimpulan yaitu sedimentasi di laguna terjadi karena pengaruh dari debit sungai Cilangla dan arus sejajar pantai Pamayangsari. Kecepatan arus sejajar pantai Pamayangsari pada Musim Barat sebesar $2.870 \mathrm{~m} /$ det, pada Musim Peralihan I sebesar $2.483 \mathrm{~m} / \mathrm{det}$, pada Musim Timur sebesar 2.565, dan pada Musim Peralihan II sebesar $3.097 \mathrm{~m} / \mathrm{det}$. Hasil nilai laju sedimentasi tertinggi yaitu di stasiun tiga sebesar $12.496 \mathrm{gr} / \mathrm{m}^{2} /$ hari dan nilai laju sedimentasi terendah yaitu di stasiun empat sebesar $10.494 \mathrm{gr} / \mathrm{m}^{2} /$ hari dengan jenis sedimen yang didominasi oleh pasir.

\section{DAFTAR PUSTAKA}

Alwan, M. A. 2010. Mekanisme Transpor Sedimen. Dikutip tanggal 24 Maret 2020: http://sedimentologiduaribusembilan.blogspot.com/2010/12/mekanisme-transportasisedimen.html

Arifin, S. 2005. Strategi untuk Mengurangi Kerusakan Lingkungan yang Diakibatkan oleh Gempa dan Gelombang Tsunami. Jurnal Arsitektur ATRIUM, 2 (1): 28-33.

Aritonang, A.E., H. Surbakti., I. Purwiyanto. 2016. Laju Pengendapan Sedimen Di Pulau Anakan Muara Sungai Banyuasin, Sumatra Selatan. Jurnal Maspari, 6 (2): 7 - 14.

Ayunarita, S., Elizal dan M. Galib. 2017. The Study Of Current Pattern, Tides And Waves On The Beaches Village Pangke Villagers Meral Karimun District Riau Archipelago Province. 
Badan Perencanaan dan Pembangunan Daerah Kabupaten Tasikmalaya. 2017. RKPD Kabupaten Tasikmalaya.

Daruwedho, H., B. Sasmito dan F. Janu. 2016. Analisis Pola Arus Laut Permukaan Perairan Indonesia dengan Menggunakan Satelit Altimetri Jason-2. Jurnal Geodesi Undip, 5 (2): 147.

Dewadaru, D. P., Hariadi dan S. Saputro. 2014. Kajian Morfologi Pantai di Pantai Slamaran Kabupaten Pekalongan. Journal of Oceanography, 3(1): 2.

Dean, R. G dan Dalrymple, R. A. 2004. Coastal Processes with Engineering Applications. Cambridge University Press, United Kingdom: $21-32$ p.

Elliott, M dan Whitfield, A. K. 2011. Challenging Paradigms in Estuarine Ecology and Management. Estuarine, Coastal and Shelf Science Elsevier, 94: 307 p.

Hidayat, N. 2005. Kajian Hidro-Oseanografi untuk Deteksi Proses - Proses Fisik di Pantai. Jurnal SMARTek, 3 (2): 73-85.

Holme, N.A dan Intyre, Mc. A.D. 1984. Methods for The Study of Marine Benthos. Backwall Scientific Publications, Oxford: 140-216 p.

Backwall Scientific Publications, Oxford: 140-216 p.

Indarmawan, T dan A. Manan. 2011. Pemantauan Lingkungan Estuaria Perancak Berdasarkan Sebaran Makrobenthos. Jurnal Ilmiah dan Perikanan dan Kelautan, 3 (2): 215 - 216.

Irawati I., E. Y. Handoko dan I. M. Anjasmara. 2008. Studi Variasi Temporal Distribusi Massa Air Menggunakan Data Water Thickness Satelit Grace. Jurnal Teknik, 4 (1): 3.

Koesoemadinata, Dr. R. P. 1985. Prinsip - Prinsip Sedimentasi. Bandung: Jurusan Geologi Institut Teknologi Bandung.

Komar, P.D. 1976. Beach Process and Sedimentation. Prentice-Hall Inc, New Jersey.

Lobeck, A. K. 1939. Geomorphology: An Introduction to The Study of Landscapes. New York: Mc Graw - Hill Book Company. 353 p.

Martono. 2009. Karakteristik dan Variabilitas Bulanan Angin Permukaan di Perairan Samudera Hindia. Makara Sains, 13 (2): $157-162$.

Neno A. K., H. Harijanto., dan A. Wahid. 2016. Hubungan Debit Air dan Tinggi Muka Air di Sungai Lambagu Kecamatan Tawaeli Kota Palu. Jurnal Warta Rimba, 4 (2): 1-2.

Nugrahayu, F. L. 2015. Estuaria (Muara). Dikutip 24 Maret 2020: http://ferisa3k1.blogspot.com/2015/03/estuarimuara.html

Pettijohn, F. J. 1975. Sedimentary Rocks.Harper\& Row. Publishers: New York, Evanston, San Fransisco, and London. 640 pages.

Pinto, Z. 2015. Kajian Perilaku Masyarakat Pesisir yang Mengakibatkan Kerusakan Lingkungan. Jurnal Wilayah dan Lingkungan, 3 (3): 163-164.

Pipkin, B.W. 1977. Laboratory Ecercise In Oceanography. W.H Freeman and Company. New Jersey.

Salahuddin, C. Fandeli dan E. Sugiharto. 2012. Kajian Pencemaran Lingkungan di Tambak Udang Delta Mahakam. Jurnal Teknosains, 2(1): 34.

Saputra, O., Y. N. Ihsan., L. P. Sari dan Y. Mulyani. 2017. Sedimentasi dan Sebaran Makrozoobentos Di Kawasan Laguna Segara Anakan Nusakambangan, Cilacap. Jurnal Perikanan dan Kelautan, VIII (1): 27.

Srijati, S., B. Rochaddi dan S. Widada. 2017. Analisis Laju Sedimentasi di Perairan Muara Sungai Waridin Kabupaten Kendal. Jurnal Oseanografi, 6 (1): 252.

Sugiyono. 2008. Metode Penelitian Pendekatan Kuantitatif, Kualitatif, dan R\&D. Bandung: Alfabeta.

Sukardjo. 1985. Kimia Anorganik. Jakarta: Bina Aksara.

Susanna, A. S. 2007. Oseanografi. Badan Riset Kelautan dan Perikanan, Jakarta.

Supriharyono. 2007. Konservasi Ekosistem Sumberdaya Hayati di Wilayah Pesisir dan Laut Tropis. Pustaka Pelajar: Yogyakarta.

Suryani, D. D. U., I. Pratikto, dan Koesoemadji. 2013. Studi Potensi Pantai Pamayangsari di Kabupaten Tasikmalaya untuk Pengembangan Wisata Bahari. Journal of Marine Research, 2 (3): 124.

Tikno, S. 2000. Analisis Debit di Daerah Aliran Sungai Batanghari Provinsi Jambi. Jurnal Sains dan Teknologi Modifikasi Cuaca, 1 (1): 102. 
Triatmodjo, B. Prof. Dr. Ir. 1999. Teknik Pantai. Yogyakarta: Beta Offset.

Williams. 2013. Waves. Dikutip 9 Oktober 2019: https://pt.slideshare.net/mswilliams/waves-notes28619255/13? smtNoRedir=1.

Wilopo, M. D. 2005. Karakter Fisik Oseanografi di Perairan Barat Sumatera dan Selatan JawaSumbawa dari Data Satelit Multi Sensor. Hal 3.

Zahid, A., C. P. H. Simanjutak., M. F. Rahardjo dan Sulistiono. 2011. Iktiofauna Eskosistem Estuari Mayangan, Jawa Barat. Jurnal Iktiologi Indonesia, 11 (1): 77. 